TOLEDO, J.C. et al. Avaliação do teor de lipídios no leite orgânico em uma propriedade do Triângulo Mineiro, MG. PUBVET, Londrina, V. 6, N. 7, Ed. 194, Art. 1305, 2012.

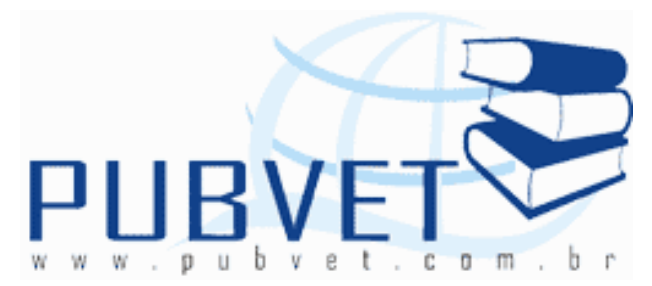

PUBVET, Publicações em Medicina Veterinária e Zootecnia.

\title{
Avaliação do teor de lipídios no leite orgânico em uma propriedade do Triângulo Mineiro, MG.
}

\author{
Juliana Capello Toledo1; Renata Dias Rodrigues ${ }^{1}$; Rafael Rocha de Souza ${ }^{2}$; \\ Marcus Vinícius Alves da Silva ${ }^{1}$
}

${ }^{1}$ Graduandos em Medicina Veterinária. Universidade Federal de Uberlândia, MG.

${ }^{2}$ Residente de Patologia Clínica Veterinária. Universidade Federal de Uberlândia, MG.

\section{Resumo}

Orgânico pode ser definido como aquele alimento produzido em sistema no qual não se faz uso de agrotóxico sintético ou outros insumos artificiais tóxicos e organismos geneticamente modificados. Existem poucos dados disponíveis sobre leite orgânico na literatura, mas há indicações de que este apresenta maior teor nutritivo quando comparado ao leite produzido em sistema convencional. O objetivo deste trabalho foi caracterizar o teor de lipídios do leite orgânico oriundos de uma propriedade localizada na mesorregião do Triângulo Mineiro-MG. As amostras de leite foram aleatoriamente coletadas de 28 fêmeas bovinas em lactação nos meses de fevereiro, maio, agosto e novembro de 2010. A análise do teor de lipídios apresentou diferenças significativas quando comparadas como valores para leite convencional. 
TOLEDO, J.C. et al. Avaliação do teor de lipídios no leite orgânico em uma propriedade do Triângulo Mineiro, MG. PUBVET, Londrina, V. 6, N. 7, Ed. 194, Art. 1305, 2012.

Podendo este fato ser associado a diversos fatores: a dieta dos animais, raças e estágio da lactação, entre outros.

Palavras-chave: Ácidos graxos. Agronegócio. Composição.

\title{
Evaluation of the lipid content in organic milk on a farm in Triângulo Mineiro, MG.
}

\begin{abstract}
Organic can be defined as that produced food system that does not use synthetic pesticides or other toxic artificial inputs and genetically modified organisms. There are few data available on organic milk in the literature, but there are indications that this has a higher nutritional content compared to milk produced in the conventional system. The objective of this study was to characterize the lipid content of organic milk from a property located in the middle region of Minas Gerais-MG. The milk samples were randomly collected from 28 lactating cows in the months of February, May, August and November 2010. The analysis of lipid content showed significant differences when compared to values for conventional milk. This fact may be related to several factors: the animals' diet, breed and stage of lactation, among others.
\end{abstract}

Keywords: Fatty acids. Agribusiness. Composition.

\section{INTRODUÇÃO}

No Brasil, apesar do leite orgânico não representar nem $1 \%$ da produção de leite (FAGUNDES, 2005) o produto lácteo começa a ganhar destaque (CAMPOS, 2004). A demanda não para de crescer, e muitas das vezes superam a oferta (FAGUNDES, 2005). A deficiência de produção se deve a diversos fatores como a falta de trabalhos de extensão rural viabilizando o processo para pequenos produtores, a carência de pesquisas científicas adequando a produção animal no sistema orgânico à realidade tropical, além da alimentação, adubação de pastagens, padrões raciais, cuidados sanitários 
TOLEDO, J.C. et al. Avaliação do teor de lipídios no leite orgânico em uma propriedade do Triângulo Mineiro, MG. PUBVET, Londrina, V. 6, N. 7, Ed. 194, Art. 1305, 2012.

com o rebanho, como controle de endo e ectoparasitos e mastites (ALVES, 2005).

A produção orgânica está regulamentada nacionalmente pela Lei no 10.831 , de 23 de dezembro de 2003 (BRASIL, 2002) regulamentada pelo Decreto no 6.323 de 27 de dezembro de 2007 (BRASIL, 2007), que dispõe sobre a agricultura orgânica e dá outras providências e objetiva a oferta de produtos saudáveis, de elevado valor nutricional, isentos de contaminantes que ponham em risco a saúde do consumidor, do agricultor e do meio ambiente. A legislação não estabelece padrões para a qualidade do leite produzido nesse sistema. No entanto, os parâmetros de qualidade do leite produzido e comercializado no país são definidos pela Instrução Normativa n51 (IN51) (BRASIL, 2003), servindo como indicativos para a produção orgânica.

O objetivo deste trabalho foi avaliar se a produção de leite orgânico influencia nos valores que quantificam o teor de lipídios neste alimento.

\section{MATERIAL E MÉTODOS}

O trabalho foi desenvolvido em uma propriedade rural com área total de 105 hectares, situada no município de Ituiutaba, a 300 km de Uberlândia, no oeste de Minas Gerais, na mesorregião do Triângulo Mineiro e Alto Paranaíba. Segundo Soares (2002) a altitude máxima do município é de 769 metros e a mínima esta entre 550 e 604 metros, e, as coordenadas são: 1858'09" de latitude e $49^{\circ} 27^{\prime} 53^{\prime \prime}$ longitude.

Com um rebanho de 33 vacas gir e girolandos aproximadamente, caracteriza-se como pequena produtora de leite orgânico, com menos de 300 litros/dia. A região possui o domínio do bioma de Cerrado, segundo Klink (2005) com o clima estacional, onde um período chuvoso, que dura de outubro a março, é seguida por um período seco, de abril a setembro, com precipitação média anual é de $1.500 \mathrm{~mm}$. O proprietário adquiriu-a em 1999, com produção leiteira 
TOLEDO, J.C. et al. Avaliação do teor de lipídios no leite orgânico em uma propriedade do Triângulo Mineiro, MG. PUBVET, Londrina, V. 6, N. 7, Ed. 194, Art. 1305, 2012.

convencional, ocorrendo à conversão para produção orgânica e aprovação em 2000 pela certificadora do Instituto Biodinâmico.

As amostras de leite foram aleatoriamente coletadas de 28 fêmeas em lactação nos meses de fevereiro, maio, agosto e novembro de 2010. Foram acondicionadas em frascos de polietileno devidamente limpos e íntegros, com uma amostra de $250 \mathrm{ml}$ de leite, devidamente refrigeradas em recipientes isotérmicos e encaminhadas, ao Laboratório de Controle de Qualidade e Segurança Alimentar, da Faculdade de Medicina Veterinária da Universidade Federal de Uberlândia.

A análise físico-química realizada permitiu avaliar o teor de lipídios pelo método butirométrico para leite fluído, de acordo com os padrões da regulamentação por disposição do MAPA, na IN nº 68.

\section{RESULTADOS E DISCUSSÃO}

O teor de gordura presente nas amostras teve uma variação de no mínimo $3,10 \%$ e máximo de $8,10 \%$, com uma média de 5,67\%, 6,03\%,6,67\%, $5,01 \%$ para fevereiro, maio, agosto e novembro e com média total de $5,84 \%$. Observou-se um teor de gordura acima dos limites estabelecidos pela IN 51 , de 3,00\%.

Em Fanti et al. (2008), foram encontrados os seguintes resultados, 2,67\%; $3,30 \% ; 3,03 \%$ e $3,32 \%$ em diferentes épocas do ano. Estes autores relatam componentes saudáveis da gordura láctea, tais como o ácido linoléico conjugado. No estudo de Fernandez et al. (2009) os resultados em coletas em propriedade ecológica no Rio Grande do Sul foi de 3,14\% de gordura. No presente estudo foi observado o teor de gordura maior do que as médias relatadas. Segundo Harding (1995) e Block (2000), o teor de gordura no leite varia em razão de diferenças entre raças e estágio da lactação, tornando esta variável mais instável que os percentuais de proteína e lactose. A dieta dos animais também pode ser manipulada para causar variações nos componentes 
TOLEDO, J.C. et al. Avaliação do teor de lipídios no leite orgânico em uma propriedade do Triângulo Mineiro, MG. PUBVET, Londrina, V. 6, N. 7, Ed. 194, Art. 1305, 2012.

do leite, e o teor de gordura pode variar em até 3\%. Nos animais criados em sistema orgânico, a alimentação é predominantemente em pastos, enquanto que no sistema convencional a alimentação baseia-se também em grãos e bolo de soja.

\section{CONCLUSÃO}

Neste estudo a escolha do sistema de manejo orgânico mostrou-se atuante na composição química, de modo que o teor de lipídeos mostrou-se elevado podendo também ter outras interferências como: a sazonalidade, raças e estágio da lactação.

\section{REFERÊNCIAS}

Alves A.A. 2005. Panorama atual da produção orgânica de leite no Brasil. Revta Agroecol. Hoje 29:24-25.

BLOCK, E. Nutrição de vacas leiteiras e composição do leite. In: ENCONTRO ANUAL DO CONSELHO BRASILEIRO DE QUALIDADE DO LEITE, 1, 2000, Curitiba. Anais... Curitiba: Centro Integrado dos empresários e trabalhadores das Indústrias do Paraná, FIEP, 2000. p. 85-88.

BRASIL. Ministério da Agricultura, Pecuária e Abastecimento. 2002. Instrução Normativa no. 51, de 18 de setembro de 2002. Aprova os Regulamentos Técnicos de Produção, Identidade e Qualidade do Leite tipo A, do Leite tipo B, do Leite tipo C, do Leite Pasteurizado e do Leite Cru Refrigerado e o Regulamento Técnico da Coleta de Leite Cru Refrigerado e

seu Transporte a Granel. Disponível em: <http://extranet.agricultura.gov.br/sislegisconsulta/consultarLegislacao>.

Acessado em 10/2007.

BRASIL. Ministério da Agricultura, Pecuária e Abastecimento. 2003. Lei 10.831, de 23 de dezembro de 2003. Dispõem sobre a agricultura orgânica e dá outras providências. Disponível em: <http://extranet.agricultura.gov.br/sislegis-consulta/ consultarLegislacao>. Acessado em 10/2007.

BRASIL. Ministério da Agricultura Pecuária e do Abastecimento. 2007. Decreto no 6.323, de 27 de Dezembro de 2007. Regulamenta a Lei no 10.831, de 23 de dezembro de 2003, que dispõe sobre a agricultura orgânica, e dá outras providências. Diário Oficial da União de 27 de Dezembro de 2007, Seção 1, página 2, Brasília, DF. Capturado em: 25 jun. 2007. Online. Disponível

em:

http://www.agricultura.gov.br/pls/portal/docs/PAGE/MAPA/MENU_LATERAL/AGRICULTURA_ PECUARIA/PRODUTOS_ORGANICOS/AO_LEGISLACAO/DECRETO\%206323.PDF 
CAMPOS E.P.C. Qualidade microbiológica, físico-química e pesquisa de resíduos de antibióticos e pesticidas no leite bovino produzido pelo sistema convencional e pelo sistema orgânico. (Dissertação de Mestrado) Faculdade de Medicina Veterinária e Zootecnia, Unesp,Botucatu. 58p. 2004.

FANTI, M. G. N. et al. Contribuição ao estudo das características físico-químicas e da fração lipídica do leite orgânico. Ciência e Tecnologia de Alimento, Campinas, 28(Supl.): 259-265, dez. 2008.

FAGUNDES, V. Pesquisas que orientam a produção, que ganha adeptos e promete aumentar os lucros no campo. 2003. Disponível em: $<$ http;//revista.fapemig.Br/matéria.php?id=205>. Acessado em julho de 2011.

FERNANDEZ V. N. V., ZANELA M. B., PINTO A. T. \& RIBEIRO M. E. R.. Qualidade do leite ecológico produzido em uma unidade de produção do Rio Grande do Sul. Acta Scientiae Veterinariae, Porto Alegre, v. 37, n.1, p 45-48. 2009.

HARDING, F. Compositional quality: milk quality. Glasgow: Blackie Academic Professional, 1995. 165 p.

SOARES, B. R; BESSA, K. C. F. O. Considerações sobre a dinâmica demográfica na região do Triângulo Mineiro/ Alto Paranaíba. Revista on line: Caminhos de Geografia. Uberlândia, jun. 2002. 